\title{
Correspondence
}

\section{Health research on the Irish in Britain}

Sir: Leavey et al (Psychiatric Bulletin, December 1997, 21, 739-740) emphasise the mental health needs of the Irish and 'wonder' why they are an invisible group. As author of the section on ethnic minorities in London's Mental Health (Johnson et al, 1997), I wish to correct and then expand on their observation. In fact, the Irish community were mentioned in the chapter on service provision for ethnic minorities in relation to higher rates of suicide and unemployment (Johnson et al, 1997; pp. 147 \& 153).

I agree that generally the Irish are neglected as a subject of research and service development. Leavey et al point this out without embarking on the more arduous task of exploring why this is the case. I think the explanation for a lack of attention to Irish mental health, in the context of ethnic minority mental health, lies in the way we define ethnicity. Specifically, "the Irish are not an ethnic group in the census although they are considered as such by virtue of the place of birth question" (Peach, 1996; p. 13). Ethnic categories are ascriptively mobilised by those within and outside of specific groupings. This is a social and political process which serves the purpose of the group or society or both (Jenkins, 1997; pp. 1011). The use of ethnic categories by the health service, which is also a political process, is intended to be the first of many stages to improve services for ethnic groups that the health service providers and planners recognise to have distinct needs. Services for Whites, Asian-Indians or Black-Caribbeans are inevitably inadequately specified as each of these categories contain a diversity of culturally distinct groups. The Irish communities' more specific needs are 'hidden' by their inclusion within the 'White' ethnic group; this lack of precision deprives the Irish of separate and adequate consideration. The UK census is like those of other European countries in that it does not invite identification of indigenous ethnic minority populations as if such a distinction is meaningless (Peach, 1996; p. 18). In addition, an anti-racist agenda is often linked, albeit sometimes inappropriately, to ethnic minority mental health issues. There is certainly prejudice against White minorities but this might not be linked to anti-racist driven service developments and research. In London's Mental Health I discuss the disadvantages faced by White immigrants (Johnson et al, 1997). The Irish, European refugees and other White groups lose out on dedicated research and service-based action.

If there is widespread agreement that ethnic categories are too arbitrary to be of value, then there might be room for more meaningful study of cultures and sub-cultures. We need to know more about self-categorisation theory, social identity theory and ethnic categorisation for the purpose of meaningful policy and planning. The Irish, I hope, will then receive more attention as one of the many neglected cultural groups, but they are not alone. Future service developments to meet mental health care needs must be multiculturally effective; they must retain the flexibility to adapt to more specific ethnicities and cultures. This was emphasised in London's Mental Health; the promotion of one groups needs over and above those of another was not the intention. Such an approach is not comprehensive, sustainable or ethical.

JENKINS, R. (1997) Rethinking Ethnicity. Arguments and Explorations. London: Sage.

JohnSON, S., RAMSAY, R., THORNICROFT, G., et al (eds) (1997) London's Mental Health: The Report to the King's Fund London Commission. London: King's Fund Institute.

PEACH, C. (1996) Ethnicity in the 1991 Census. Volume 1. Demographic Characteristics of the Ethnic Minority Populations. London: OPCS.

KAMALDEeP BHUI, Wellcome Training Fellow, Institute of Psychiatry, De Crespigny Park, London SE5 8AZ

\section{Definition of 'haltlose'}

Sir: Dr Cullivan (Psychiatric Bulletin. January $1998,22,58-59$ ) asks about the term 'haltlose' or 'haltlos' as a type of personality disorder in the ICD-10 Classification of Mental and Behavioural Disorders (World Health Organization, 1992).

In his German language psychiatric dictionary, Peters (1984) describes 'haltlos' psychopaths as "weak-willed, unreliable, unable to resist external influences, easily led astray, tending to sexual waywardness and prostitution. But they are also easily led in a positive sense: in an appropriate setting, and also in prison, they can be managed without difficulty. If left alone, they cannot set their own goals, they have no inner compass'."

Manfred Bleuler (1983), in the section of his textbook devoted to personality disorders, writes: "The 'haltlosen' are characterized by a lack of 
enduring emotional attachment and, thus, an abnormal tendency for the will to be influenced by various inner and outer stimuli; they 'blow hot and cold'. They range from excitable to the apathetic."

The term is also found untranslated in the French edition of the ICD-10: "F60.8 . . inclure: personnalité de type 'haltlos' . . .. But it is certainly not in widespread use in French psychiatry, and I doubt whether it is much used in Germany either.

Incidentally, 'haltlose' is just the feminine form of 'haltlos', the German word for 'personality' (Persönnlichkeit) being feminine.

BLEULER, M. (1983) Eugen Bleuler: Lehrbuch der Psychiatrie (15th edn), p. 574. Berlin: Springer-Verlag.

Peters, U. H. (1984) Wöterbuch der Psychiatrie und medizinischen Psychologie (3rd edn), p. 445. Munich: Urban and Schwarzenberg.

WORLD HEALTH ORGanIzaTION (1992) The ICD-10 Classification of Mental and Behavioural Disorders: Clinical Descriptions and Diagnostic Guidelines. Geneva: WHO.

PAUl Balley, FORENAP, Secteur 8, Centre Hospitalier, F-68250 Rouffach

\section{Financial implications of Calman changes in psychiatry}

Sir: I have sympathy with Zubin Bhagwager's (Psychiatric Bulletin. December 1997, 21, 784785) comments about the financial implications of Calman implementation in postgraduate training, having previously expressed concerned about the way the College implemented the changes (Double, 1994). I understand the College having taken the approach of minimal change and I do think that it can be proud of its structure of general professional and specialist training. However, I find it difficult to see the motivation for change in the present structure and I do think it needs to move on to meet the needs of current mental health training and services.

The balance between general professional and specialist training is wrong, as I previously argued. Clinical responsibility should be delegated to trainees on the basis of experience and still too much is expected of senior house officers, while their specialist and senior registrar colleagues are able to take advantage of their 'supernumerary' status. As training develops in other specialities, I think this contrast is likely to become more transparent and adversely affect recruitment to psychiatry.

Moreover, general professional training is still too hospital based. The College with some foresight several years ago produced a report by David Julier on The Implications for Training of a Shift to a Community Orientated Service', but this report seems to have had little impact and anyway was never radical enough about the introduction of community psychiatry. One of the factors for the present malaise and scandal of mental health services may be the attitudes and practices of consultant psychiatrists. It is difficult to change this situation without introducing proper community psychiatric training at the beginning of structured training, which may require more of an overhaul of training structures than the College seems prepared to contemplate.

Double, D. B. (1994) The Calman Report on specialist training. Psychiatric Bulletin, 18, 699.

D. B. Double, Consultant Psychiatrist, Norfolk Mental Health Care NHS Trust, Hellesdon Hospital, Drayton High Raod, Norwich NR6 5BE

\section{Psychiatry and the WWW: some implications}

Sir: Senior et als article (Psychiatric Bulletin, December 1997, 21, 775-778) clearly highlights the increasing role the World Wide Web will play in future psychiatric practice and research. One interesting dimension is its use by psychiatric patients. Many of our patients with Chronic Fatigue Syndrome (CFS) have used the information disseminated on the CFS web-site and benefited from it. Concern has been expressed, though, about the range and quality of the information that is available on-line and about the effect on patients of accessing such data sites. The Internet has an important role to play in every aspect of patient care including interviewing patients but caution must be exercised in the extent to which we 'mechanise' such a purely human interaction as a psychiatric interview.

We recurrently assessed a female patient who had taken a potentially serious overdose of simple analgesic and antidepressant tablets with alcohol and left a message on the Internet, meant to be a 'suicide note'. This message was picked up by a stranger in the United States, who fortunately alerted the British police. The patient was alsone at home but the police broke into her house about five hours after the overdose attempt and brought her to the accident and emergency department. Her life was saved because of the 'electronic suicide note' and the presence of mind of the person who picked it up and alerted the police across the Atlantic.

This incident raises some interesting points. First, if this method increases in popularity, this could be very risky as such messages may not be picked up, taken seriously or acted upon. Second, it gives a clue to the high intentionality 